\title{
Vigilante justice and police protocols in the Latin American south cone
}

\begin{abstract}
There is a wide debate worldwide, and particularly in Latin America with respect to citizen insecurity and the proliferation of more punitive claims from the society itself. In this article we analyze the attitude of the citizens belonging to the countries of the Latin American South Cone towards maintaining the law regarding persecuting and punishing criminals. In particular, we tackle the approval of vigilante justice in some circumstances and the justification of police procedures outside the law as a form of guaranteeing the capture of criminals. For this, we use the LAPOP (Latin American Public Opinion Project, Vanderbilt University) database from the year 2008. Analyzing the data using profit estimations, we observe that the approval of vigilante justice is related to the experience and particular situation of the respondent. In this sense, having been victimized in the last months and feeling unsafe in his or her own neighborhood increase the probability of taking that position regarding vigilantism. On the other side, sticking to police procedures is more strongly related to the general political beliefs and the level of concern for the respondents' insecurity. These findings indicate that the formation of these beliefs has a differential dynamic and that when actions outside the law have to be justified; this is distinguished based on the type of involved action and the actor who carries it forward.
\end{abstract}

Keywords: vigilantism, police procedures, law, south cone, justice, political beliefs, punitivism, JEL Classification: K4, K14, P37
Volume I Issue I - 2017

\author{
Maximo Rossi,' Cecilia Chouhy, ${ }^{2}$ Andlrene \\ Mussio, ${ }^{2}$ Fernando Borraz ${ }^{3}$ \\ 'Department of Economics, University of the Republic and \\ Center for Inter-American Policy and Research, Tulane \\ University, Uruguay \\ ${ }^{2}$ Department of Economics, University of the Republic, Uruguay \\ ${ }^{3}$ Department of Economics, Central Bank of Uruguay, Uruguay
}

Correspondence: Maximo Rossi, Departament of Economics, University of the Republic, Uruguay,

Email maximo.rossi@gmail.com

Received: April 28, 2017| Published: June 19, 2017

\section{Introduction}

In recent years, debate on insecurity in the media and as part of public opinion has been of increasing importance in both political and academic spheres. Even while explanations of the origin of this situation are varied and there is no consensus about its causes, the relevance of this issue has been broadly acknowledged and it has gained a preponderant place in the public agenda. However, the lack of reliable data on violence, crime and police procedures has been one of the most important hurdles related to research on the subject, as government agencies have failed to produce valid statistics and statistics usually reflect under-reporting. Given this, recent studies on crime and violence focused on individual attitudes and not on crime figures. Individuals' attitudes regarding crime and punishment in contemporary society have been approached from several perspectives and in different countries and regions. ${ }^{1}$ In particular, many papers analyze the link between punitive attitudes and the fact of individuals having been victim of a crime in the last year. ${ }^{2-5}$ Findings are often contradictory and depend on the country of interest and the data source considered.

This article analyzes the attitudes of South Cone inhabitants regarding the maintenance of law in the prosecution and punishment of offenders. Specifically, it addresses respondents' approval of people taking justice into their own hands in some circumstances and the justification of police action outside the law when capturing suspected criminals. Particular attention is given to the link between individual victimization and such attitudes towards justice along with the beliefs in an ideological and philosophical sense. Data from the LAPOP (Latin American Public Opinion Project, Vanderbilt University) conducted in 2008 is used for this purpose. The paper goes as follows: section 2 discusses prior literature on justice, punitivism and the use of vigilante justice. Section 3 details the data used and methodology applied to analyze the issue. Section 4 discusses the results and section 5 concludes.

\section{Previous studies}

Establishing whether there has been an actual punitive turn in contemporary societies has been a frequent point of debate in the specialized literature. The "get tough" policy approach consolidated in the 70s, when many governments adopted measures of this sort that, among other things, ended up substantially increasing prison populations while failing in combating crime. ${ }^{6}$

Various authors emphasize the character of such an ostensible punishment, not only expected to serve as an example for the rest of society but also associated with the dismantling of the welfare state and a consolidation of rightwing governments in the developed world. In this kind of analysis, the role of public opinion is oftentimes emphasized and increasingly punitive attitudes from the public over time, in support of such policies, are commonly assumed.

However, these categorical assertions about public opinion are questionable in at least two ways. First, there is no consensus regarding the construction of measures of public opinion. ${ }^{8-10}$ indifferent kinds of studies, discuss the robustness and validity of measures from public opinion polls and despite the differences between their studies, the findings coincide on the fact that opinion polls are conditioned to the way questions are constructed and that changes in the stimuli may lead to differing conclusions.

Hough \& Roberts ${ }^{10}$ critique traditional public opinion polls in addressing the fact that measurements, being too focused on attitudes, tend to ignore basic issues such as public visibility of both alternative 
sanctions and actual judicial behavior. Analyzing both elements together, they conclude that public attitudes read as punitive are mainly associated with not only the respondent's ignorance concerning alternative measures but also with his or her overestimating of judicial indulgence.

Nagin et al. ${ }^{9}$ discuss the common assumption of public opinion supporting certain budget expenditures in punitive "getting tough" measures. For this purpose, they conduct a population survey focused on measuring the public willingness to pay for alternative policies such as detention or rehabilitation. With this data, they conclude that, given two policies -one punitive and one rehabilitative oriented-with similar out comes, public preferences are largely indifferent. For juvenile populations, however, the public indicates a high willingness to pay (WTP) for preventive policies.

Empirical studies conducted using traditional approaches to public opinion are not conclusive on whether there has been a punitive turn in public attitudes. Study conclusions vary depending on the type of information used and the region of reference.

In this regard, several studies analyze international survey data, particularly the International Crime Victimization Survey (ICVS), European Crime and Safety Survey (EU ICS), Latin American Population Survey (LAPOP), etc. Other studies use data from surveys designed by the researchers. ${ }^{11,3}$

Van Dijk et al..$^{5}$ analyzecross-country differences and conclude that it is in the UK where the more prevalent positions in favor punitive policies are encountered. When contrasting these findings with imprisonment rates, the association between these two elements becomes less conclusive.

Mayhew \& van Kesteren ${ }^{4}$ focus on the analysis of the different punitive attitudes of the population of each region in the world and its relationship with the type of policies developed in regions. Latin America falls the global average, inhabitants of the developed world tending to have fewer punitive demands and African inhabitants claiming for stronger average sanctions. From these findings they conclude that economic development has much to do with these types of claims and that it is in countries with lower levels of development where additional incarceration has higher levels of support. The consolidated punitive tradition of Anglo phone countries makes them the only exception, where support prison sentences are higher than in the rest of the developed world.

Mayhew \& van Kesteren ${ }^{4}$ conclude, using the ICVS survey data that parameters such as sex, age and educational level, correlate strongly with the punitiveness of attitudes of the population. Perception of insecurity and having been a victim of theft present small correlations in some cases, but do not have a significant effect in all regions, so it is not possible to conclude that the fact of having been a victim of crime necessarily increases people's punitive claims.

Findings are also inconclusive when analyzing Latin America's specific situation. Di Tella \& Schargrod sky ${ }^{3}$ studied the link between punitive demands of the population and victimization in Argentina, analyzing the same sample at two different points in time. Through this kind of methodology, they were able to isolate the changes in the parameters provoked by experiencing victimization. Their results conflict with most findings in other countries, as they find that being victimized reduces the chances of adopting more punitive attitudes. This issue is explained, in the words of the authors, as a sort of victim's "Stockholm syndrome", in a situation where they tend to sympathize more with social inequities and thus claim for solutions such as expanded employment opportunities and better educational opportunities. Also, they found that an association between victimization and not holding punitive attitudes was correlated with having leftist beliefs. Also, being a victim of crime is correlated with thinking that the effort does not pay.

Demombynes $^{2}$ work provides a strong point of reference for the current study. The conclusions drawn from this paper differ greatly from those of Di Tella and Schargrodsky ${ }^{3}$ in their analysis of the situation of Latin America using the LAPOP 2008 survey. In addition to punitivism, in this case the study focuses on people's attitudes toward several crime related items such as the justice system particularly attitudes towards institutions-, approval of people taking justice into their own hands (vigilantism) and the belief that police authorities may act within the law under certain circumstances.

In terms of the relationship between such attitudes and demographic variables, the author observes that trusting the justice system is more frequent among nonwhites, the more educated and the poorer, and decreases with age at a decreasing rate. With regard to authorities abiding the law, support for this statement is higher among men, whites, married and richer, and also diminishes with age at a decreasing rate.

Dembombynes' paper focuses on the relationship between having experienced a situation of victimization and the adoption of the attitudes described which are particularly large in societies with rising crime rates. Analyzing the changes in attitudes and victimization, the conclusion drawn is that suffering such an event reduces confidence in justice, increases the adoption of vigilantism and decreases the belief that the authorities always have to respect the law. The results differ among the countries considered and not all parameters are significant.

The findings of both Demombynes ${ }^{2}$, Di Tella \& Schargrodsky ${ }^{3}$ assume that such attitudes are directly related to actions taken by the state. However, a direct relationship between demands of the population and punitive policy implemented by governments is an issue which remains unaddressed. The relationship between individuals' attitudes with regard to punishment and the actual implementation of punitive policies in this regard is unclear, and has also been debated in the academy.

Di Tellaand Dubra ${ }^{12}$ studied the increase in punitiveness by comparing prison rates in different countries and conclude that "tough hand" policies are associated with people believing in individual opportunity and the rewards of working hard. Thus, they associate punitivism with ideologies and beliefs, addressing the differences between the United States and Europe. Van Dijk et al. ${ }^{5}$ analyze European samples with specific questions about punishment, and conclude that no significant relationship between imprisonment rates and punitive attitudes on the part of the public can be established. Similar conclusions are drawn by Mayhew and van Kesteren ${ }^{4}$ who, when analyzing the link between public approval and use of punitive measures by the justice system, found no significant effect between the different regions considered.

A direct antecedent of the current study is the one conducted by Borraz et al., ${ }^{13}$ in which the focus was to further analyze the determinants of both support for vigilantism and for police disregard for legal procedures when dealing with suspects and/or offenders in Uruguay. The study found that support for each issue had a different 
set of determinants, in the case of vigilantism being related to experience (e.g. victimization) and in the case of support for police acting outside legal margins being related to general philosophical and ideological orientations. The purpose of the present study is to extend this previous research to the situation in the South Cone and to establish whether these conclusions generally hold across the entire region.

In short, it is important to study specifically this kind of attitude for the case of the South Cone and to seek to deepen the understanding of the factors that best explain the adoption of such beliefs by the public. In particular, it is crucial to take into account the effect of victimization on the public, simultaneously addressing the factors that explain it. Once those issues are addressed, it will be possible to discuss the potential impact of such findings when thinking about changes in actions of the criminal justice system and the political system. Nevertheless, caution will be needed when discussing possible relationships between attitudes and policies and when debating potential future scenarios.

\section{Methodology and data}

\section{i) Data}

Data on crime and victimization cause controversy across the world. There is great discussion about which source types are best to estimate the level of crime in a given society and about how accurate official records are in this regard. Both victimization surveys and self-reported data sources are widely used in the developed world, where periodic measurements are made from these instruments. These measurements also include questions that reveal interviewee's considerations regarding their opinion on optimal punishments. Beyond entering into the controversy over which data are most valid for estimating crime, it is important to highlight the poor development of these instruments in Latin America.

Measurements of victimization have been incorporated into

Table I Description of variables international surveys, which are carried out in almost all of Latin America (LAPOP, Gallup, and Latino barometer).

These surveys differ in the way they formulate victimization questions, each of which requires a different analysis. Specifically, the Latino barometer questionnaire asks about the victimization of either the respondent or of a relative, while the Gallup Poll focuses on the household's victimization and the LAPOP only on the individual's. These differences affect victimization estimates because they involved the use of different units of analysis.

In this article, we seek to understand the effect of victimization on people's attitudes. For this reason, we decided to use the LAPOP database, which explores individual-level victimization. While it is possible to think that the victimization of any household member may also generate a second-hand experience likely to influence the attitude of respondents about the rule of law when it comes to punishing offenders, it is most convenient to analyze the isolated effect of personal victimization, which is also the most reliable data. ${ }^{14}$ The survey also includes variables measured at the individual level that will allow a better understanding of the importance of other attitudes on punitiveness and enrich the explanatory power of the model.

\section{ii) Methodology}

We focused on the explanation of two different attitudes: individual's approval of people taking justice into their own hands (vigilantism) and approval of police violating lawful procedures in order to capture and question suspected offenders. Different profit models are estimated for the probability of individuals approving of such things. Both dependent variables are taken as binary type, with Disapprove $=0$ and Approve $=1$. Separate models were constructed to predict each dependent variable.

Table 1shows the definition of the variables that are incorporated into the model. As shown, in addition to the variables that refer directly to attitudes and experiences related to crime and insecurity, the direct object of the present work, other variables are also included Table 1.

\begin{tabular}{|c|c|}
\hline Variable & Label \\
\hline Police Protocols & $\begin{array}{l}\text { In order to apprehend criminals do you think that the authorities should always respect the law or that occasionally they } \\
\text { can skate close to the limits of the law? ( } I \text { if can act on the margins occasionally) }\end{array}$ \\
\hline Vigilantism & $\begin{array}{l}\text { Of people taking the law into their own hands when the government does not punish criminals. How much do you approve } \\
\text { or disapprove? (I if approves) }\end{array}$ \\
\hline Victim & Have you been a victim of any type of crime in the past 12 months? (( $I$ if yes) \\
\hline Insecurity & $\begin{array}{l}\text { Speaking of the neighborhood where you live, and thinking of the possibility of being assaulted or robbed, do you feel very } \\
\text { safe, somewhat safe, somewhat unsafe or very unsafe?(I if somewhat unsafe/very unsafe) }\end{array}$ \\
\hline Homo & $\begin{array}{l}\text { And now, changing the topic and thinking of homosexuals, how strongly do you approve or disapprove of such people being } \\
\text { permitted to run for public office? (I if disapprove) }\end{array}$ \\
\hline Left & $\begin{array}{l}\text { According to the meaning that the terms "left" and "right" have for you, and thinking of your own political leanings, where } \\
\text { would you place yourself on this scale? Indicate the box that comes closest to your own position. ( } I \text { if left, I } 10 \text { right) }\end{array}$ \\
\hline Es_good & $\begin{array}{l}\text { How would you describe your overall economic situation? Would you say that it is very good or good? (Ordinal variable: } \\
\text { good, neutral or bad) }\end{array}$ \\
\hline Es_neutral & $\begin{array}{l}\text { How would you describe your overall economic situation? Would you say that it is neither good nor bad (Ordinal variable: } \\
\text { good, neutral or bad) }\end{array}$ \\
\hline Es_improve & Is your economic situation better than in the last twelve months? \\
\hline Female & I if female \\
\hline Age & Age in age brackets $(16-25,26-35,36-45,46-55,56-65,65+)$ \\
\hline
\end{tabular}




\begin{tabular}{ll}
\hline Table Continued.... & \\
\hline Variable & Label \\
\hline Education & Years of education \\
Married & I if married \\
Divorced & I if divorced \\
Widow & I if widow \\
Wealths & Wealth index according to LAPOP methodology' \\
Biggercity & I if lives in a big city \\
Catholic & I if catholic \\
Evangelist & I if evangelic \\
Attend & I if attends religious services at least once a week
\end{tabular}

On the one hand, traditional demographic variables such as gender, age and socioeconomic status, are included as control variables. Their inclusion also allows us to visualize differences between sub-populations. Moreover, we include variables relating to general attitudes, which account for orientations with regard to philosophy of life (ideological self-identification, tolerance towards homosexuality, religion, etc.). Finally, we include measures of individuals' selfevaluations of their conditions, specifically their economic situation and whether it has improved, and fear of crime. Those variables are often considered as determinants of the attitudes of respondents to variables of working interest. ${ }^{3}$

\section{Results}

First, it is important to analyze the overall levels of approval of the elements considered in each of the countries considered. Looking at Table 2 it can be observed that the position of the countries in terms of their percentage approval differs depending on the question considered. The average approval on both issues among the South Cone countries is lower than the total Latin American average. Still, there is a great difference within this group in terms of approval of police acting in the margins of the law. Uruguay, Paraguay and Chile show much higher than average percentages of approval while Brazil's and Argentina's approval is less than average.

This situation is striking, as Uruguay, for example, usually shows high levels of respect for law and confidence in judicial institutions. Further research in order to address the relationship between individual approval of such issues and actual outcomes regarding police and judicial actions must be conducted. Surveys are often influenced by what people perceive is occurring in the country. People may perceive that lawful procedures are being taken too seriously and thus claim for a change, in the belief that procedures against the law are being sub-utilized. Hough \& Roberts ${ }^{10}$ findings about punitive claims are in line with this kind of reasoning. According to them punitive claims emerged when people had misleading -and underestimatedperceptions of how judges were acting. In order to assess the impact of country-level determinants such as those previously presented, further research shall be developed Table 2 .

Table 2 Percentage of approval of procedures outside the law, by country

\begin{tabular}{lllll}
\hline \multirow{2}{*}{ Country } & \multicolumn{2}{c}{ Vigilantism } & \multicolumn{3}{c}{ Police protocols } \\
\cline { 2 - 5 } & \% Approval & Position & \% Approval & Position \\
\hline Argentina & 25.81 & 11 & 37.32 & 12 \\
Brasil & 12.95 & 20 & 28.9 & 18 \\
Chile & 27.2 & 8 & 48.62 & 5 \\
Paraguay & 16.62 & 19 & 48.66 & 4 \\
Uruguay & 22.43 & 12 & 49.83 & 3 \\
AverageLatin American countries & 24.82 & & 39.37 & \\
South Coneaverage & 21 & & 35.56 & \\
Total & 24.99 & & 38.85 & \\
\hline
\end{tabular}

We estimate three different models for each of the dependent variables, which are built by progressively incorporating the different groups of independent variables we considered (Table 3). We control for country fixed effects (Uruguay being the omitted variable) and aim for robust errors by using country-based clusters Table 3 .

In estimating coefficients of determinants of the two dependent variables, the age parameter is significant and indicates negative marginal effects in the different specifications of the model. This means that, in general, the older the person is, the less will approve of actions outside the legal parameters, specifically regarding police procedures and vigilante justice.

In the case of education, the coefficient is significant and negative only in the case of vigilantism. Contrary to the results by age and education levels, we highlight the lack of significance of variables which are traditionally used to evaluate attitudinal differences, such as gender and the income percentile of the household of the surveyed individual. 
Table 3 Marginal effects of probit estimations

\begin{tabular}{|c|c|c|c|c|c|c|c|c|}
\hline & $-I$ & -2 & -3 & -4 & -5 & -6 & -7 & -8 \\
\hline \multicolumn{5}{|l|}{ Vigilantism } & \multicolumn{4}{|c|}{ Police protocols } \\
\hline \multirow[t]{2}{*}{ Victim } & & $0.199 * * *$ & $0.163 * * *$ & $0.201 * * *$ & & 0.077 & 0.026 & $-0.118 * *$ \\
\hline & & [0.039] & [0.028] & [0.025] & & [0.069] & [0.054] & [0.045] \\
\hline \multirow[t]{2}{*}{ Insecurity } & & & $0.151 *$ & $0.149 *$ & & & $0.228 * * *$ & $0.229 * * *$ \\
\hline & & & {$[0.061]$} & {$[0.062]$} & & & [0.058] & {$[0.057]$} \\
\hline \multirow[t]{2}{*}{ Female } & 0.007 & -0.002 & -0.006 & -0.007 & 0.001 & 0.004 & 0.007 & 0.007 \\
\hline & {$[0.057]$} & {$[0.054]$} & {$[0.060]$} & {$[0.060]$} & {$[0.044]$} & {$[0.04 I]$} & [0.038] & {$[0.038]$} \\
\hline \multirow[t]{2}{*}{ Age } & $-0.009 * *$ & $-0.009 * *$ & $-0.009 * *$ & $-0.009 * *$ & $-0.008 * * *$ & $-0.007^{* * * *}$ & $-0.008 * * *$ & $-0.008 * * *$ \\
\hline & [0.003] & [0.003] & [0.003] & [0.003] & {$[0.002]$} & {$[0.002]$} & {$[0.002]$} & {$[0.002]$} \\
\hline \multirow[t]{2}{*}{ Education } & $-0.026 * *$ & $-0.028 * *$ & $-0.028 * * *$ & $-0.028 * * *$ & -0.014 & -0.014 & -0.01 & -0.01 \\
\hline & [0.009] & [0.009] & {$[0.008]$} & {$[0.008]$} & [0.009] & [0.009] & {$[0.008]$} & [0.008] \\
\hline \multirow[t]{2}{*}{ Married } & -0.065 & -0.07 & -0.074 & -0.076 & $0.097 *$ & $0.098^{*}$ & 0.095 & 0.091 \\
\hline & {$[0.055]$} & [0.058] & [0.068] & [0.068] & [0.048] & [0.048] & {$[0.050]$} & [0.05I] \\
\hline \multirow[t]{2}{*}{ Divorced } & 0.078 & 0.064 & 0.056 & 0.055 & 0.04 & 0.049 & 0.059 & 0.055 \\
\hline & [0.083] & {$[0.084]$} & {$[0.073]$} & {$[0.073]$} & {$[0.076]$} & {$[0.075]$} & {$[0.078]$} & {$[0.079]$} \\
\hline \multirow[t]{2}{*}{ Widow } & -0.064 & -0.057 & -0.052 & -0.051 & 0.104 & 0.098 & 0.105 & 0.101 \\
\hline & [0.094] & {$[0.092]$} & {$[0.105]$} & {$[0.106]$} & {$[0.112]$} & {$[0.112]$} & {$[0.116]$} & {$[0.116]$} \\
\hline \multirow[t]{2}{*}{ Wealths } & -0.018 & -0.018 & -0.003 & -0.002 & 0.009 & 0.01 & 0.018 & 0.018 \\
\hline & {$[0.011]$} & {$[0.012]$} & {$[0.020]$} & {$[0.020]$} & {$[0.024]$} & [0.024] & [0.023] & [0.023] \\
\hline \multirow[t]{2}{*}{ Biggercity } & 0.13 & 0.118 & 0.091 & 0.089 & -0.044 & -0.049 & -0.089 & -0.083 \\
\hline & [0.083] & [0.088] & [0.092] & [0.092] & {$[0.050]$} & {$[0.050]$} & {$[0.046]$} & [0.044] \\
\hline \multirow[t]{2}{*}{ Catholic } & -0.129 & -0.132 & -0.121 & -0.122 & 0.005 & 0.007 & 0.003 & 0.005 \\
\hline & [0.084] & [0.083] & [0.085] & [0.085] & [0.07I] & {$[0.070]$} & {$[0.070]$} & [0.069] \\
\hline \multirow[t]{2}{*}{ Evangelist } & $-0.213 * * *$ & $-0.206 * * *$ & $-0.186 * * *$ & $-0.186 * * *$ & -0.05 I & -0.04 & -0.052 & -0.054 \\
\hline & [0.047] & {$[0.04 I]$} & {$[0.04 I]$} & [0.043] & [0.092] & {$[0.087]$} & [0.087] & [0.087] \\
\hline \multirow[t]{2}{*}{ Attend } & $-0.129 * * *$ & $-0.128 * * *$ & $-0.119 * *$ & $-0.120 * *$ & -0.069 & -0.075 & $-0.088^{*}$ & $-0.09 \mid *$ \\
\hline & {$[0.036]$} & [0.039] & {$[0.040]$} & [0.039] & {$[0.04 I]$} & {$[0.042]$} & [0.038] & [0.039] \\
\hline \multirow[t]{2}{*}{ Left } & 0.015 & 0.014 & 0.016 & 0.017 & $0.034 *$ & $0.033^{*}$ & $0.030 *$ & $0.030 *$ \\
\hline & {$[0.010]$} & {$[0.010]$} & {$[0.011]$} & {$[0.011]$} & {$[0.016]$} & {$[0.016]$} & [0.015] & [0.015] \\
\hline \multirow[t]{2}{*}{ Argentina } & 0.057 & 0.046 & 0.006 & -0.002 & $-0.405^{* * *}$ & $-0.415^{* * * *}$ & $-0.450 * * *$ & $-0.523 * * *$ \\
\hline & [0.044] & [0.042] & {$[0.030]$} & [0.033] & [0.0I4] & [0.0I5] & [0.032] & {$[0.036]$} \\
\hline \multirow[t]{2}{*}{ Brasil } & $-0.346 * * *$ & $-0.328 * * *$ & $-0.306 * * *$ & $-0.269 * * *$ & $-0.636 * * *$ & $-0.642 * * *$ & $-0.640 * * *$ & $-0.662^{* * * *}$ \\
\hline & {$[0.03 \mathrm{I}]$} & {$[0.034]$} & {$[0.04 I]$} & [0.039] & {$[0.050]$} & {$[0.05 \mathrm{I}]$} & [0.055] & {$[0.050]$} \\
\hline \multirow[t]{2}{*}{ Chile } & $0.229 * * *$ & $0.234 * * *$ & $0.235^{* * *}$ & $0.256 * * *$ & $-0.035 * * *$ & $-0.036 * * *$ & $-0.078 * * *$ & $-0.14 \mid * * *$ \\
\hline & {$[0.020]$} & {$[0.020]$} & {$[0.017]$} & {$[0.011]$} & [0.009] & {$[0.010]$} & {$[0.020]$} & {$[0.022]$} \\
\hline \multirow[t]{2}{*}{ Paraguay } & $-0.193 * *$ & $-0.186 * *$ & -0.153 & -0.154 & $-0.04 I$ & -0.036 & -0.078 & -0.079 \\
\hline & {$[0.067]$} & {$[0.070]$} & [0.086] & [0.082] & [0.072] & [0.073] & [0.093] & [0.088] \\
\hline \multirow[t]{2}{*}{ Es_good } & & & -0.148 & -0.148 & & & -0.058 & -0.057 \\
\hline & & & {$[0.119]$} & {$[0.120]$} & & & {$[0.072]$} & {$[0.07 I]$} \\
\hline \multirow[t]{2}{*}{ Es_neutral } & & & -0.107 & -0.105 & & & -0.027 & -0.027 \\
\hline & & & [0.09I] & [0.092] & & & [0.05I] & [0.05I] \\
\hline Es_improve & & & 0.03 & 0.032 & & & $0.049 *$ & $0.047^{*}$ \\
\hline
\end{tabular}


Table Continued....

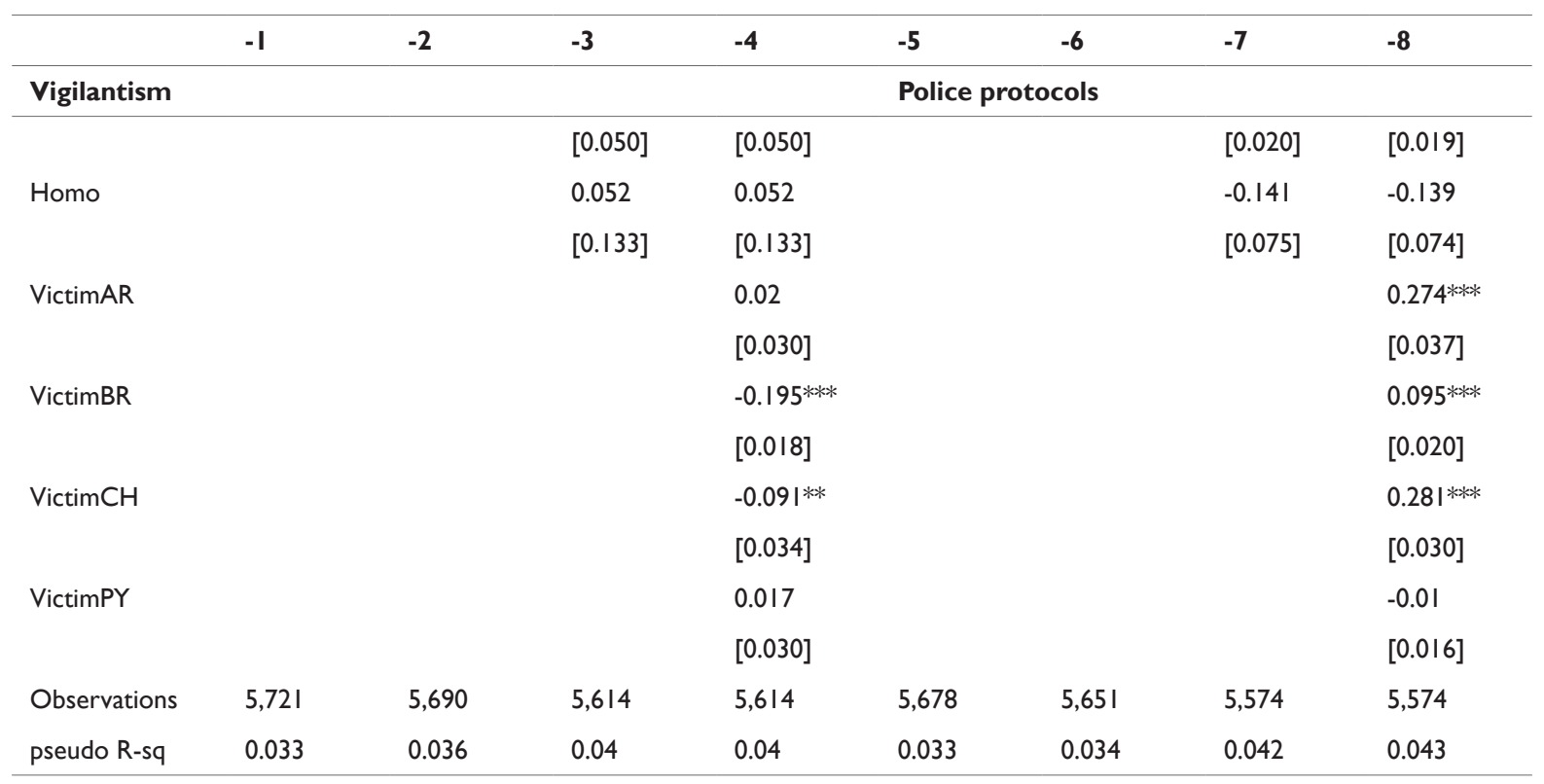

Note: Uruguay is the excluded country control variable. Country-cluster errors are considered.

In addition, the estimated models incorporate a set of variables related to the specific situation of the individual, attitudes towards crime and life philosophy. The results for these variables different depending on by the dependent variable considered in each model. To start with, we analyze the estimation for vigilantism. In this case, the significant variables are related to the perception of the individual's own situation, whether insecurity or economic uncertainty.

The victimization parameter is significant and positive, which means that having been a victim of a crime in the last 12 months increases the probability that the individual approves of vigilante justice $(+5.8 \mathrm{pp}$ based on the means of coefficients of the other variables in the second model and $+4.7 \mathrm{pp}$ in the third model). The individual's declaration that he or she feels insecure in the neighborhood they live in is positively related to approval of vigilantism. In this case, the reported marginal effect is higher, at around $+4.2 \mathrm{pp}$. The significance and direction of these two parameters highlight the relationship between the agreement with vigilante justice and the individual's own experiences with crime. Not only when individuals have a direct experience with crime but also when they feel particularly vulnerable and insecure, it is more likely for them to feel that vigilante justice is legitimate or empathize with those who exercise it. Negative experiences form a basis for more punitive beliefs ${ }^{1}$.

In this respect, results are then similar to those of Borrazet al. ${ }^{13}$ and also contradict the observation made by Di Tella \& Schargrodsky, ${ }^{3}$ who concluded about the existence of a "Stockholm syndrome" effect, determining that the victimized individual held less punitive beliefs. It should be noted that in this case, the authors are not analyzing punitivism in some aggregate manner based on synthetic measures, but they estimate explanatory models of particular aspects comprising punitivism and which do not necessarily have the same determinants as a synthetic measure.

However, results are different from those obtained in Borraz et al. ${ }^{13}$ in two respects. First, in this model, the variables related to the economic situation of the individual are not significant. Second, it

${ }^{1}$ This relationship will have to be studied in more depth in future studies, with the aim of establishing controls which consider the potential endogeneity of the variables involved and which enable to estimate causal relationships. is important to highlight the impact of religion and religiosity in the approval of vigilante justice in this model. Individuals who are more religious (attend religious services frequently) are less likely to approve of the use of vigilante justice. The associated parameter is significant and the marginal effect is quite similar between specifications (around 3.5pp). Among religions, Catholicism does not have a significant impact but Evangelicalism does. The associated coefficient for this last variable is significant and has a negative impact (around 5pp).

Similar to what was found for the case of Uruguay Borraz et al., ${ }^{13}$ results are quite different when we estimate a model with police protocolsas the dependent variable. In this case, the variables which are significant are not indicative of the individual's experience but instead of his or her general beliefs and philosophical and ideological postures. Specifically, the ideological self-positioning scale is significant. The reported marginal effect establishes that positioning one additional point to the right is associated with a $1.3 \mathrm{pp}$ increase in the probability of approving of these types of procedures. Insecurity also operates in the same direction, increasing the probability of agreeing with police procedures outside the law by $8.9 \mathrm{pp}$.

The probability differential is also affected by the married dummy variable, which has a positive effect. Also, there is a lower probability of holding a positive attitude with regard to these two variables among those who approve that homosexuals can hold public jobs. The findings of Borraz et al. ${ }^{13}$ are corroborated elsewhere. Despite some changes in terms of which variables are significant, both the specific model estimated for Uruguay and the South Cone model show that the classification proposed by Ingle hart et al. ${ }^{15}$ regarding cultural orientations could itself be influencing this aspect. Ingle hart et al. ${ }^{15}$ proposes an alternative way to understand cultural differences beyond the traditional ideological axis. In this sense, the type of cultural orientation - towards survival or self-expression - appears to be relevant when trying to explain several punitive attitudes.

In post-industrial societies, the overcoming of certain economic uncertainties led to a change in values, a product of a new set of preoccupations no longer related to economic security but to subjective well-being, quality of life and self-expression. ${ }^{16,17}$ where 
some non-traditional lifestyles, such as homosexuality, seem to be more tolerant. In the countries where these economic goals have not been reached, cultural orientations centered in survival prevail, where traditional values associated with family are preponderant and where there is more intolerance towards alternative organizations. The hybrid character that these processes have acquired in Latin America has been strongly pointed out. This is a region where these new cultural orientations coexist with traditional orientations, in a scenario where economic uncertainties persist. ${ }^{18,19}$ This is the framework where our findings seem indicative of a differentiation no longer based on the traditional sense of ideology but on a different axis. Being married increases the probability of being in favor of not respecting police procedures alongside tolerance to homosexuality having the opposite effect could seem as two independent facts, but they are accounting for the fact that this axis seems to be classifying lifestyles which lead to different attitudes towards crime. Lastly, we find that religiosity has a negative and significant impact on such attitudes regarding police protocols (approximately $3 \mathrm{pp}$ ).

\section{Conclusion}

Based on the prior analysis, it is possible to state several conclusions. On the one hand, it is important to highlight the high percentage of the population in the South Cone who agree with statements that validate the not-strictly-sticking to the established legal frames when it comes to fighting crime.

In accordance with previous findings, we observed that the explanation underlying a positive attitude towards vigilante justice in the Latin American South Cone is strongly linked to the respondent's personal experience. In particular, it is based on both objective (previous victimization) and subjective (sensation of insecurity) contributors to individuals experiencing vulnerability to crime.

This can be compared to considerations regarding police action and their respect towards legal procedures when it comes to pursuing suspects, which seem to be explained by other reasons. In this case, it depends more on the respondent's philosophy of life and their ideological beliefs. This philosophy of life transcends ideological considerations in more traditional terms (left-right affiliation) and involves cultural orientations, located in a self-expression-survival axis. $^{20}$

These cultural elements or philosophy of life, etc., contribute evidence to be accounted for when evaluating the respondent's overall attitudes. Many of the highlighted studies use synthetic indicators of the concept of punitivism as a dependent variable, and these indicators are used in different models. This research therefore alerts future investigations to such concerns, as it contributes evidence that apparently similar attitudes may involve different underlying elements. This means that the concept to be evaluated should be treated with caution.

Finally, the concept of punitivism itself involves a wide variety of aspects of a given society, one of which related to opinions of the public. When determining punitive attitudes of individuals it is important to incorporate several points of view on the subject; it is also key to account for the different aspects which involve it. This article has analyzed two specific opinions which provide a partial view of the topic in a specific region. Future studies should extend upon this and consider all the elements which contribute to punitiveness in public opinion in a more inclusive way.

\section{Conflict of interest}

The author declares no conflict of interest.

\section{References}

1. De la Torre V, Álvarez AM. Violencia, Estado de derecho y políticas punitivas en América Central. Mexico: PerfilesLatinoamericanos, Enero-juni; 2011.18 p.

2. Demombynes G. The effect of crime victimization on attitudes. USA: World Bank; 2009. 22 p.

3. Di Tella R, Schargrodsky E. Happiness, Ideology and Crime in Argentine Cities. USA: Inter-American Development Bank; 2009. 43 p.

4. Mayhew P, Van Kesteren J. Cross-National Attitudes to Punishment. Findings from the 2000 ICVS. In: Roberts M, Hough, editors. Changing Attitudes to Punishment, Public opinion, Crime and Justice. UK: Willan Publishing; 2002. $25 \mathrm{p}$.

5. Van Dijk J, Manchin R, Van Kesteren J, et al. The Burden of Crime in the EU, A Comparative Analysis of the European Survey of Crime and Safety (EU ICS) 2005. Belgium: EUICS report; 2005. 118 p.

6. Petersilia J. California's Prison Policy: Causes, Costs, and Consequences. The Prison Journal. 1992;72(1-2):8-36.

7. Matthews R. The myth of punitiveness. Theoretical Criminology. 2005;9(2):175-201.

8. Piquero AR, Steinberg L. Public preferences for rehabilitation versus incarceration of juvenile offenders. Journal of Criminal Justice. 2010;38(1):1-6.

9. Nagin DS, Piquero AR, Scott ES, et al. Public Preferences for Rehabilitation versus Incarceration of Juvenile Offenders: Evidence From a Contingent Valuation Survey. Criminology and Public Policy. 2006;5(4):627-651.

10. Hough M, Roberts JV. Sentencing trends in Britain Public knowledge and public opinion. Secretary. 1999;1(1):11-26.

11. Briceño-León R, Ávila O, Camardiel A. Inseguridad y violencia en Venezuela. 1st ed. Venezuela; 2009.

12. Di Tella R, Dubra J. Free to Punish? The American Dream and the Harsh Treatment of Prisoners. Cambridge: NBER Working Paper No. 17309; $2011.53 \mathrm{p}$

13. Borraz F, Chouhy C, Rossi M. Victimización y justicia por mano propia en Uruguay. Uruguay: Documentos de Trabajo DECON; 2012. 23 p.

14. Gottfredson MR, Hindelang MJ. Sociological aspects of criminal victimization. Review Literature And Arts Of The Americas. 2010;7(1981):107-128.

15. Inglehart $\mathrm{R}$, Norris $\mathrm{P}$, Welzel C. Gender equality and democracy. Comparative Sociology. 2002;1(3):321-345.

16. Inglehart R. Modernization and Postmodernization. USA: Princeton University Press; 1997.

17. Adamczyk A, Pitt C. Shaping attitudes about homosexuality: The role of religion and cultural context. Social Science Research. 2009;38(2):338351 .

18. Garretón A. Política, cultura y sociedad en la transición democrática. USA: Nueva sociedad; 2002. 12 p.

19. Lechner N. Los patios interiores de la democracia. Subjetividad $y$ política. USA: FLACSO; 1988.

20. Inglehart R. Culture Shift. USA: University of Chicago Press; 1990.

\section{Acknowledgements}

None. 